\title{
Notes on the Occurrence of the Bamboo Pitviper, Trimeresurus gramineus (Reptilia: Squamata: Viperidae), from Southwestern West Bengal, India
}

Subhadeep Chowdhury ${ }^{1}$, Arpita Dutta ${ }^{2}$, Anirban Chaudhuri ${ }^{3}$, and Sudip Ghosh ${ }^{4}$

${ }^{1}$ Krishnachak, Dhurkhali, Howrah, West Bengal, India (isuvodeep@gmail.com)

${ }^{2} 1 / 211$, Jodhpur Park, Kolkata, West Bengal, India

${ }^{3} 6 / 7$, Nature Mates, Bijoygarh, Jadavpur, Kolkata, West Bengal, India

${ }^{4}$ 24/1 Jagannath Ghosh Road, Kolkata, West Bengal, India

$\mathrm{T}$

The Bamboo Pitviper, Trimeresurus gramineus (Shaw 1802 ), is a nocturnally-active snake that usually is associated with hilly forests. Sawant et al. (2010) reported that it appeared to prefer the thick canopy of trees at an average height of 3 to $5 \mathrm{~m}$ above the ground, but it also is known to inhabit low bushes and is frequently found near streams (Whitaker and Captain 2004). Many pitvipers are reportedly hygrophilic in nature (Daltry et al. 1998), which could

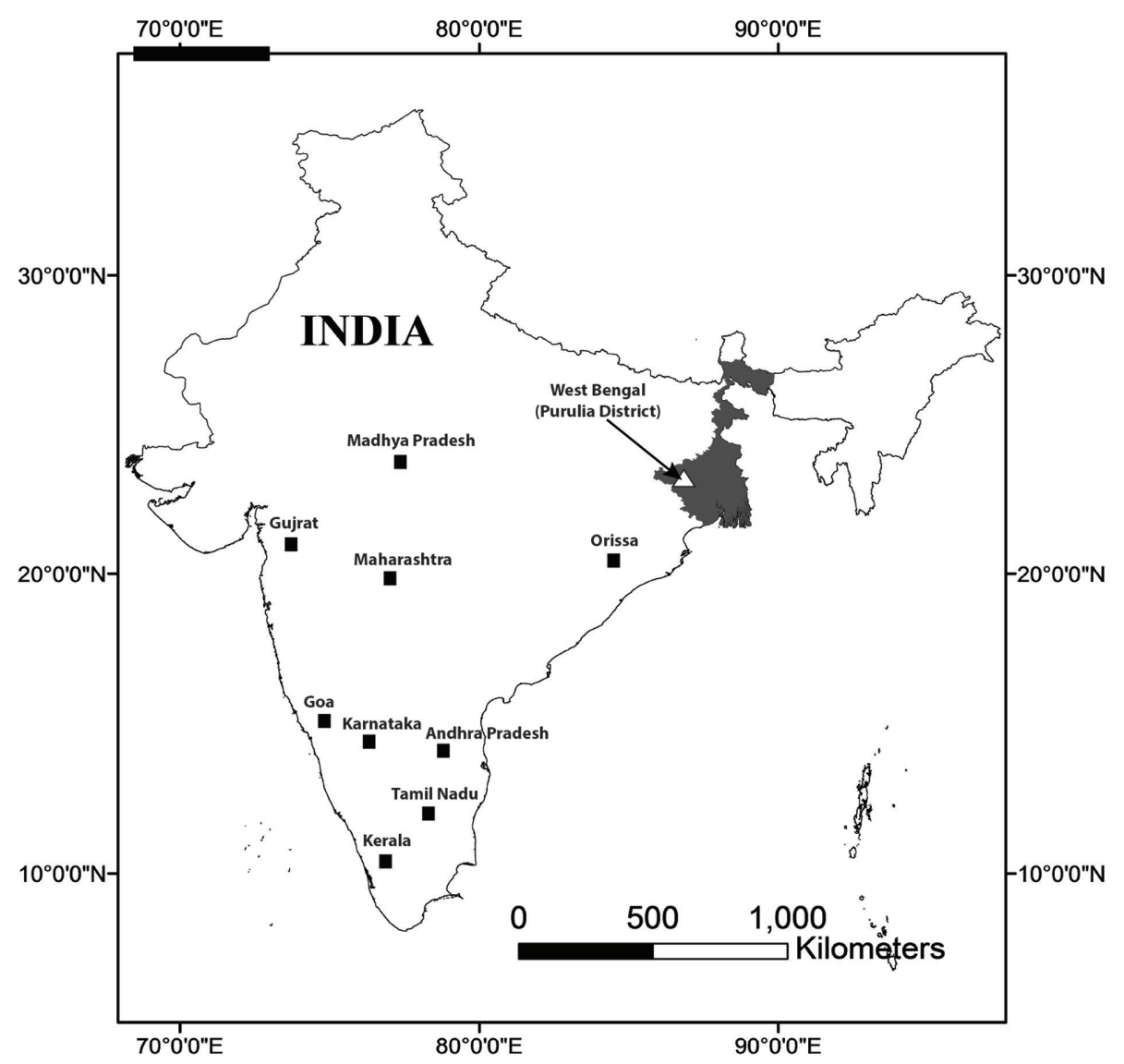

Fig. 1. Map of India showing previously reported localities (black squares) for the Bamboo Pitviper (Trimeresurus gramineus) and a new locality for Trimeresurus cf. gramineus from Purulia, West Bengal (white triangle). 
explain the presence of $T$. gramineus near streams and in moist forest habitats.

Like some other green Asian pitvipers, the Bamboo Pitviper might constitute a species complex. Because the systematics of this species have not been investigated, we subsequently refer specimens from West Bengal to Trimeresurus cf. gramineus. Morphometric data for two live specimens (Table
1) fall within the range of that for $T$. gramineus as defined in the available literature.

Trimeresurus gramineus is endemic to India, where it is known from the peninsular regions of the Western Ghats, including the states of Gujrat, Maharashtra, Goa, Karnataka, Kerala, and Tamil Nadu, and the state of Andhra Pradesh (including Shevaroy, Javadi, Seshachalam, Nallamala Hills,

Table 1. Two specimens of Trimeresurus cf. gramineus from West Bengal compared with descriptions in Smith (1943) and Whitaker and Captain (2004).

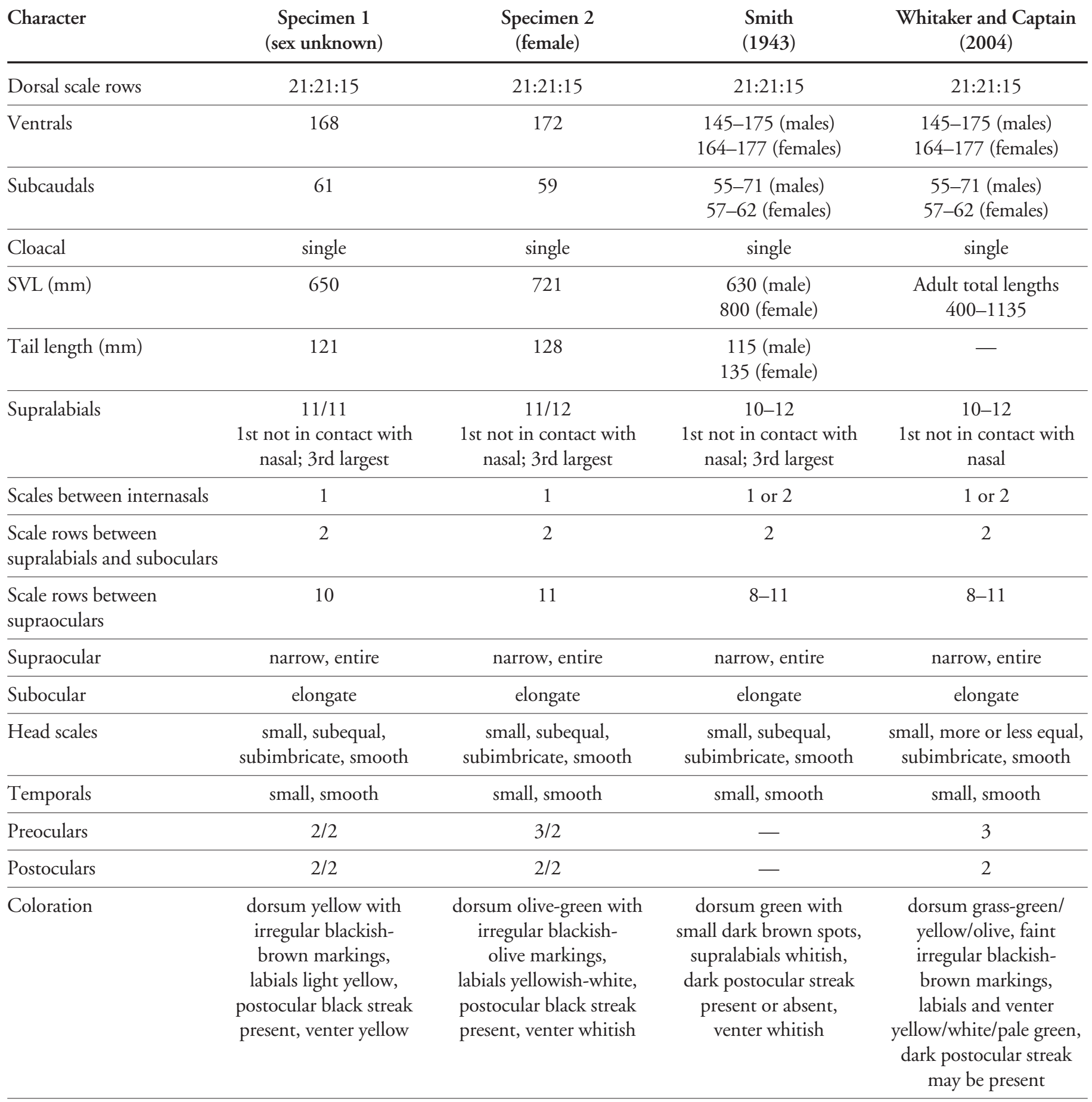




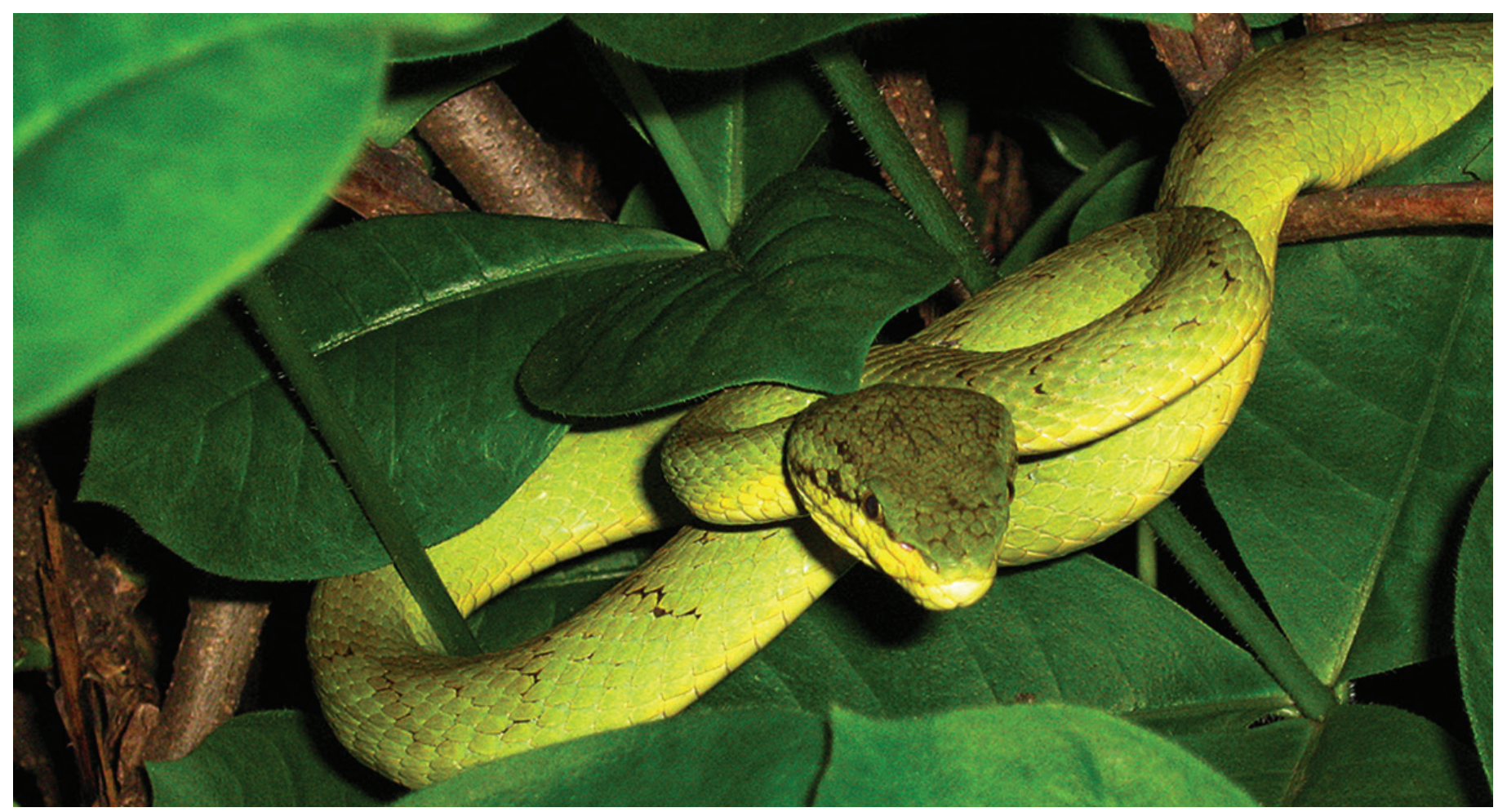

Fig. 2. Trimeresurus cf. gramineus (sex unknown) at 0149 h on 13 November 2007 in a low-lying bush 2 m above the ground in Garpanchkot (Purulia District), West Bengal, India (23.383836 N, 86.454108 E; elevation 157 m asl). Photograph by Sudip Ghosh.

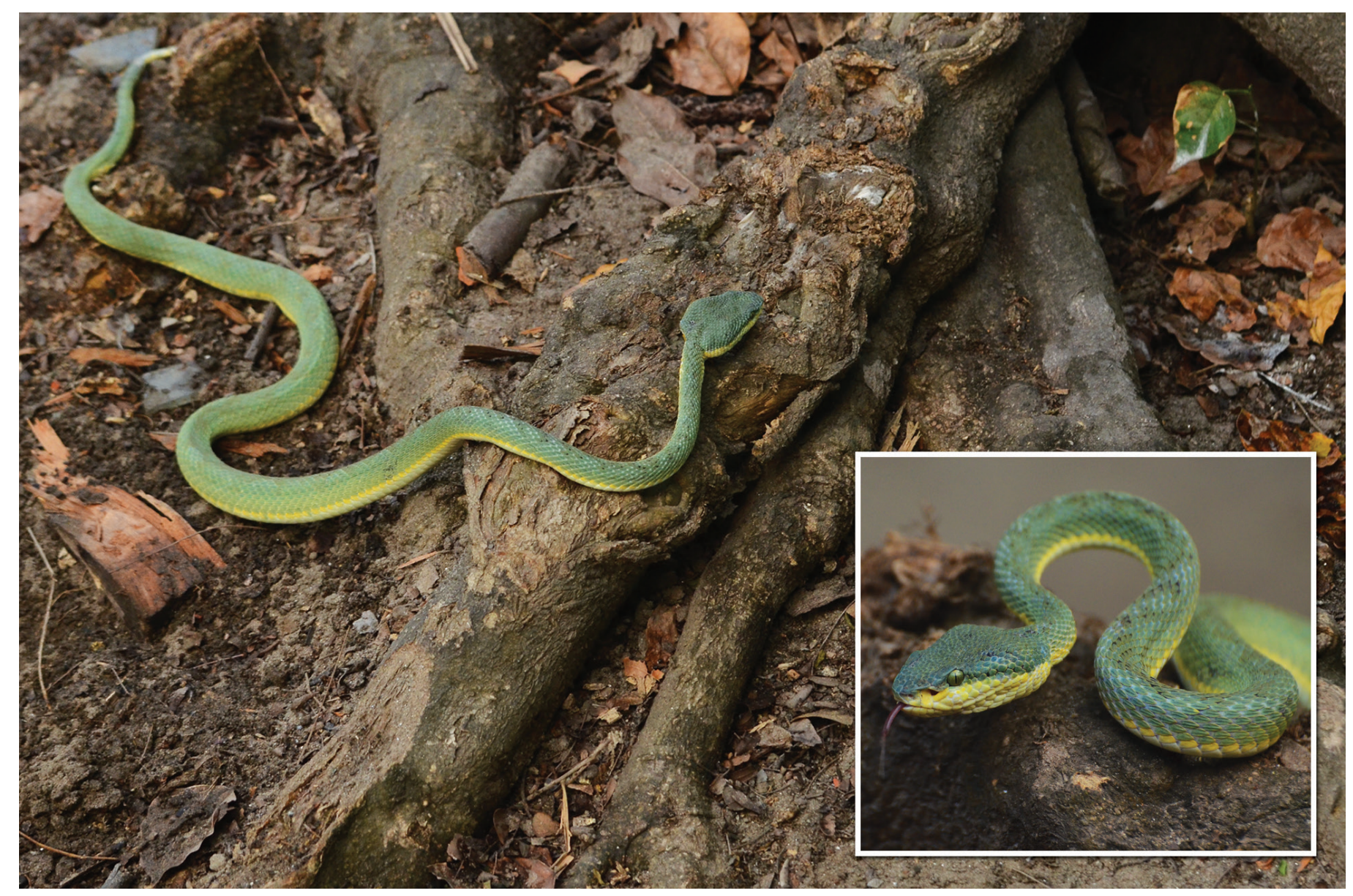

Fig. 3. Adult female Trimeresurus cf. gramineus at 1710 h on 01 February 2015 foraging on the ground in Garpanchkot (Purulia District), West Bengal, India (23.383836 N, 86.454108 E; elevation 157 m asl). Photograph by Arpita Dutta. 
and Adilabad) in the Eastern Ghats (Srinivasulu 2003; Whitaker and Captain 2004; Nande and Deshmukh 2007; Srinivasulu and Das 2008). Records of this species from the state of Orissa (Dutta et al. 2009) are not based on voucher specimens and detailed descriptions are not available. D'Abreu (1928) also recorded this species in the Pachmarhi Region, Hosangabad District in the state Madhya Pradesh.

We recorded this species on two occasions in Garpanchkot (Purulia District), West Bengal, India $\left(23.383836^{\circ} \mathrm{N}\right.$, $86.454108^{\circ} \mathrm{E}$; elevation $157 \mathrm{~m}$ asl; Fig. 1). We encountered the first snake (Fig. 2) at 0149 h on 13 November 2007 in a low-lying bush $2 \mathrm{~m}$ above the ground and the second snake (Fig. 3) at $1710 \mathrm{~h}$ on 01 February 2015 foraging on the ground near the base of a tree. These new records of $T$. gramineus extend the northeastern-most distribution approximately $230 \mathrm{~km}$ from the nearest previously recorded location in Orissa, India. More fieldwork will be necessary to determine the actual range of the species.

\section{Acknowledgements}

We thank Gernot Vogel for his input in the manuscript. We thank Rajesh Kr Sah for providing the map.

\section{Literature Cited}

D'Abreu, E.A. 1928. Record of the Nagpur Museum, No. VI. A List of Reptiles of the Central Provinces. Government Press, Nagpur, India.

Daltry, J.C., T. Ross, R.S. Thorpe, and W. Wüster. 1998. Evidence that humidity influences snake activity patterns: A field study of the Malayan Pit Viper Calloselasma rhodostoma. Ecography 21: 25-34.

Dutta, S.K., P.P. Mohapatra, and A.K. Mohapatra. 2009. Amphibians and Reptiles of Similipal Biosphere Reserve. Regional Plant Resource Centre. Bhubaneswar, Orissa, India.

Nande, R. and S. Deshmukh. 2007. Snakes of Amravati district including Melghat, Maharashtra, with important records of the Indian Egg-eater, Montane Trinket Snake and Indian Smooth Snake. Zoos' Print Journal 22: 2920-2924.

Sawant, N.S., T .D. Jadhav, and S.K. Shyama. 2010. Distribution and abundance of pit vipers (Reptilia: Viperidae) along the Western Ghats of Goa, India. Journal of Threatened Taxa 2: 1199-1204.

Shaw, G. 1802. General Zoology, or Systematic Natural History. Volume. 3, Part I. Amphibia. G. Kearsley, London.

Smith, M.A. 1943. The Fauna of British India, Ceylon, and Burma, Including the Whole of the Indo-Chinese Sub-region. Reptilia and Amphibia. Volume III, Serpentes. Taylor and Francis Ltd., London, UK.

Srinivasulu, C. 2003. Reptiles of Kawal Wildlife Sanctuary, Andhra Pradesh. Newsletter of the Reptile Network of South Asia 5: 2.

Srinivasulu, C. and I. Das. 2008. The herpetofauna of Nallamala Hills, Eastern Ghats, India: An annotated checklist, with remarks on nomenclature, taxonomy, habitat use, adaptive types and biogeography. Asiatic Herpetological Research 11: 110-131.

Whitaker, R. and A.S. Captain. 2004. Snakes of India: The Field Guide. Draco Books, Chennai, India. 